\title{
SOBRE A POLÊMICA DA ORIGEM DO DIAMANTE NA SERRA DO ESPINHAÇO (MINAS GERAIS): UM ENFOQUE MINERALÓGICO
}

\author{
MARIO LUIZ DE SÁ CARNEIRO CHAVES *, JOACHIM KARFUNKEL * \& DARCY PEDRO SVISERO **
}

\begin{abstract}
THE POLEMIC ORIGIN OF THE DIAMOND IN THE SERRA DO ESPINHA CO (MINAS GERAIS): A MINERALOGICAL $V I E W$ The origin of the diamond in the Serra do Espinhaço has been the target of exausted discussions for almost 200 years. The enigma about the primary diamondiferous source(s) conducted to several hypotheses, which can be resumed in two antagonic points of view: proximal, inside the sedimentation basin of the Espinhaço Supergroup (Mesoproterozoic), or distal, in the western lying cratonic area (Mesoproterozoic or earlier), peripherical to the sedimentation site, releasing the diamonds during the depositional record. Study of mineralogical features of the diamond and associated minerals, led to new data corroborating the second point of view concerning the origin of the gem. Analysis of the matrix of the diamond-bearing proterozoic conglomerates showed the absence of any mantle source indicators. Study of heavy mineral fractions of alluvial deposits in the same region, conduct to identical results; the analysed garnets are almandines of crustal origin. Mineralogy of representative diamond populations at several areas, show the following conclusive remarks: (1) Large crystals (>lct) are rare, totalizing less than 1\%; (2) The predominance $(90 \%)$ of "intact" crystals (not broken), outstanding rhombododecahedral, octahedral and transitional habits $(>70 \%) ;(3)$ Polycrystaline aggregates are almost absent $(<0,1 \%)$; (4) Diamond with macroinclusions (seen without a hand loup) are rare $(<5 \%)$, and $(5)$ The large predominance of gem quality diamonds (78-97\%). These features point towards a distal lying source area for the Espinhaço diamonds, outside (extra basin) the depositional site, probably within the São Francisco cratonic area.

Keywords: dianomd, mineralogy, gemology, Serra do Espinhaço.
\end{abstract}

RESUMO A origem do diamante da Serra do Espinhaço tem sido alvo de discussões por quase 200 anos. O enigma da fonte diamantífera primária na região conduziu a uma série de hipóteses díspares, as quais representam duas linhas antagônicas de pensamento a respeito desta origem: próxima, isto é, dentro da bacia de sedimentação do Supergrupo Espinhaço (mesoproterozóica), ou distante, na zona cratônica situada a oeste (mesoproterozóica ou anterior), perifericamente ao sítio deposicional, liberando o diamante durante a evolução do registro sedimentar da bacia. O estudo das principais características mineralógicas do diamante e de seus minerais acompanhantes, resultou na obtenção de novos dados que permitiram apoiar a segunda linha de pensamento sobre a origem da gema. Em relação às rochas conglomeráticas, encaixantes da mineralização na Serra, concentrados volumosos de sua matriz revelaram ser ela destituída de minerais indicadores de fonte mantélica. A mineralogia dos pesados aluvionares que ocorrem na região também não foi indicativa de quaisquer minerais mantélicos; as granadas amostradas foram determinadas como almandina de origem crustal. Quanto a mineralogia do diamante, estudos integrados de lotes representativos de diversas áreas foram conclusivos a respeito de que: (1) cristais grandes (>lct) são raros, totalizando menos que $1 \%$ em relação ao total de indivíduos amostrados; (2) cristais "inteiros" predominam largamente $(>90 \%)$, destacando-se os de hábitos rombododecaédricos, octaédricos e transicionais entre ambos $(>70 \%)$; (3) diamantes como agregados policristalinos estão praticamente ausentes $(<0,1 \%)$; (4) diamantes com macro-inclusões (visíveis a olho nu) são raros (<5\%); (5) cristais de qualidade gemológica predominam (78-97\%). A integração dos dados apresentados apontam para o transporte desde uma área fonte distante para o diamante do Espinhaço, extra-bacia, provavelmente situada na zona do Craton do São Francisco a oeste do atual espigão serrano.

Palavras-chave: diamante, mineralogia, gemologia, Serra do Espinhaço

INTRODUÇÃO A temática envolvendo a gênese e a distribuição no tempo das jazidas de diamantes brasileiras tem acumulado nos últimos dois séculos um enorme acervo de pesquisas, sendo que grande parte dos mais eminentes geólogos atuantes no país se detiveram em algum momento de sua obra neste estudo. Em Minas Gerais, quase 300 anos de lavra e mais que 30 anos de pesquisas específicas visando a detecção de rochas matrizes desta preciosa gema, não foram suficientes para se obter resultados satisfatórios a respeito.

Minas Gerais possui duas províncias diamantíferas de afinidades geográficas e geológicas características: Espinhaço e Alto Paranaíba. $\mathrm{Na}$ Província do Espinhaço, localizada na porção centro-norte do Estado e objeto do presente estudo, os principais depósitos se associam à zona serrana (Distritos de Diamantina e Grão Mogol), além daqueles situados a oeste da serra (Distrito da Serra do Cabral). Á área é limitada a leste pelo Rio Jequitinhonha e a oeste pelo Rio São Francisco (Fig. 1), com uma produção de diamantes estimada em torno de 200.000 ct/ano, cerca de $20 \%$ do total nacional (Karfunkel et al. 1994). A região do Espinhaço historicamente constitui a maior produtora de diamantes do Brasil, suplantada apenas na última década pelo norte do Mato Grosso.

Duas linhas de pensamento procuraram explicar a origem do diamante do Espinhaço: "próxima", na própria bacia de sedimentação, ou "distante", extra-bacia. O antagonismo entre elas motivou acirradas discussões e a geologia em si não tem sido suficiente para dar todas as respostas sobre o assunto. Desta forma utilizou-se a mineralogia como ferramenta objetivando abranger este complexo tema. Análises dos minerais pesados em depósitos secundários da região, bem como a caracterização dos aspectos físicos do diamante através do estudo de populações representativas de várias áreas, forneceram os subsídios para se apoiar uma das citadas linhas.

A Serra do Espinhaço em Minas Gerais tem sido alvo de dezenas de estudos recentes acerca de sua estratigrafia e tectônica, abrangendo principalmente o Supergrupo Espinhaço (unidade que sustenta a maior parte da serra), nos quais se baseiam as concepções estratigráficas ora apresentadas (p. ex., Dossin et al. 1990, Almeida-Abreu 1993,1996, Chaves 1997). Deve-se ressaltar que o estudo abrangeu exclusi- vãmente a região do Espinhaço, não tratando assim da também problemática origem do diamante do Alto Paranaíba (vide, p. ex., Tompkins \& Gonzaga 1989, Gonzaga et al. 1994).

MÉTODOS DE ESTUDO Para o estudo da mineralogia do diamante e dos seus minerais acompanhantes no Espinhaço, foram selecionadas quatro áreas diamantíferas: Diamantina (campos de Datas e do Rio Jequitinhonha), Grão Mogol e Serra do Cabral. Os levantamentos de campo envolveram o estudo de lotes de diamantes e a amostragem de minerais pesados. Os trabalhos de laboratório consistiram no seu estudo através de métodos laboratoriais específicos, tais como: microscopia óptica, difratometria e fluorescência de raios $\mathrm{X}$, microssonda eletrônica, microscopia eletrônica de varredura, espectroscopia de absorção no infravermelho e análises por ativação neutrônica. Os quatro primeiros foram aplicados aos minerais pesados, enquanto os três últimos foram utilizados para caracterizar o comportamento mineralógico do diamante. Nas áreas citadas, foram examinados lotes de diamantes em posse de comerciantes e garimpeiros locais, com lupa gemológica de 10 aumentos. Esses dados, coletados em uma tabela classificatória organizada para esse fim, foram tratados objetivando comparações entre as áreas citadas e outras do Brasil e do exterior.

Nas diversas áreas diamantíferas, a amostragem dos minerais pesados visou os dois principais tipos de depósitos da Serra do Espinhaço: os conglomerados proterozóicos das formações Sopa Brumadinho e Grão Mogol (Supergrupo Espinhaço) e os sedimentos holocênicos deles derivados. Nos conglomerados utilizou-se amostragem em canal, com seções de corte de $10 \times 5 \mathrm{~cm}$. Tendo em vista que os minerais indicadores do diamante talvez possuíssem um fator de diluição muito alto, em duas lavras ativas no Distrito de Diamantina coletou-se cerca de $10 \mathrm{~kg}$ do concentrado dejigagem (fração $<1 \mathrm{~mm}$ ). De outra maneira a amostragem dos aluviões recentes envolveu a coleta de $1 \mathrm{O}$ litros de sedimento em leito vivo por local, nas principais drenagens das áreas enfocadas. Outros detalhes sobre a metodologia de amostragem empregada encontram-se em Chaves (1997).

* Instituto de Geociências, Universidade Federal de Minas Gerais, Av. Antônio Carlos, 6627, Campus da Pampulha, CEP 31270-901, Belo Horizonte, MG, Brasil. FAX (031) 499-5410. E-mail: mchaves@igc.ufmg.br

** Instituto de Geociências, Universidade de São Paulo, Caixa Postal 11.348, CEP 05422-970, São Paulo, SP, Brasil. FAX (011) 818-4258. 


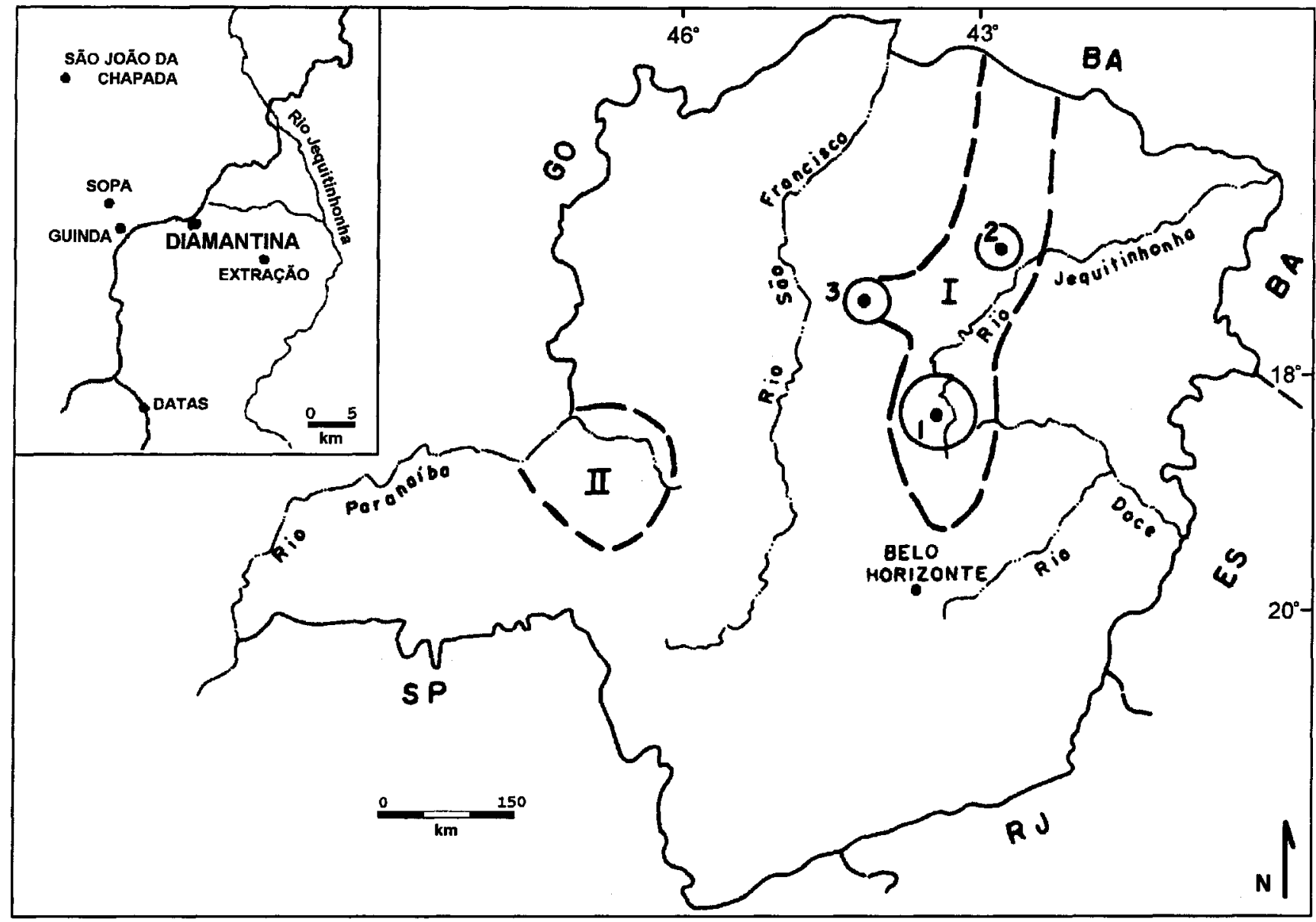

Figura 1 - Províncias diamaníferas de Minas gerais, mostrando a localização das áreas enfocadas no estudo. I) Província do Espinhaço, II) Província do Alta Paranaiba. Distritos estudados: 1) Diamantina (em detalhe no alto a esquerda), 2) Grão Mogol, 3) Serra do Cabral.

MINERAIS PESADOS O estudo dos minerais pesados que acompanham o diamante nos depósitos secundários de várias idades da Serra do Espinhaço teve como principal finalidade a determinação de possíveis minerais provenientes de kimberlitos e lamproítos. Os poucos trabalhos que trataram da descrição mineralógica desses depósitos demonstraram a inexistência de tais minerais (p. ex., Hussak 1917, Guimarães 1934, Schölll \& Turinsky 1980, Munhóz 1981). Por outro lado, o fato das amostragens nesses estudos terem sido aleatórias e/ou abrangendo volumes muito reduzidos de material, aumentava a possibilidade de que as mesmas não incluíssem algum mineral importante. Assim sendo, além da amostragem sistemática, foi dada atenção especial aos minerais mais resistentes como granadas, ilmenita e cromita. Os dois últimos minerais, no entanto, mostraram-se pouco úteis como indicadores de rochas ultrabásicas. A ilmenita é particularmente importante na prospecção do diamante, pois sua variedade rica em magnésio (4-17\% de MgO, segundo Mitchell 1986) é considerada um dos principais minerais presentes em rochas kimberlíticas. $\mathrm{Na}$ região de Diamantina esse mineral é comum, mas como ocorre freqüentemente nos veios de quartzo que cortam as seqüências regionais, não permite que seja considerado um traçador, nos aluviões, de rochas fontes daquele tipo. Entre os pontos amostrados, a ilmenita apareceu com maior freqüência no Ribeirão Datas, de onde dois grãos foram analisados com microssonda eletrônica, tratando-se de ilmenita pobre em magnésio $(\mathrm{MgO}=0-0,03 \%)$, portanto, sem interesse na prospecção diamantífera. Quanto a cromita, ela não foi determinada entre os pesados da região, embora tenha sido citada na localidade de Extração por Freise (1930). Nesta área, porém, são comuns clastos procedentes das seqüências vulcano-sedimentares pré-Espinhaço, como talco-xistos, fuchsita-quartzitos, turmalinitos e cromititos, de onde deve provir o mineral.

Desta maneira, o estudo das granadas foi enfatizado. A análise de dezenas de amostras deste mineral, porém, não indicou a presença de fases minerais relacionadas a rochas ultrabásicas, embora diversos outros minerais antes desconhecidos na região, como andaluzita, crichtonita, crisoberilo, diásporo e euclásio, tenham sido caracterizados durante a prospecção de detalhe (Chaves 1997). As granadas em geral constituem espécies pouco abundantes no Espinhaço. Na realidade, sob uma análise visual rápida, esses minerais são normalmente confundidos com zircão vermelho ou mesmo com monazita. Hussak (1917) descreveu grossulária nos aluviões de Datas, ressaltando suas características gemológicas, e espessartita na brecha de São João da Chapada. Schölll \& Turinsky (1980) observaram a ocorrência de almandina entre os pesados de uma das amostras de rochas do Supergrupo Espinhaço, mas não especificaram em qual formação. Recentemente, Chaves \& Karfunkel (1993) reconheceram granadas ocorrendo junto com euclásio em Gouveia, ao sul de Diamantina (Córrego do Capão).

A granada apresenta-se em cristais anédricos e geralmente angulosos, de colorações rósea clara a escura, com tonalidades variando do vermelho até o violeta claro. Amostras com diferentes características de cor e aspecto morfológico foram analisadas com microssonda eletrônica, mas não mostraram diferenças composicionais significativas. Os dados obtidos demonstraram que são todas granadas da espécie almandina, em percentagens variáveis do mineral entre $69,8-75,3 \% \mathrm{em}$ peso (Chaves 1997). Essas granadas possuem origem crustal, sem portanto qualquer relação com os diamantes às quais se associam nos depósitos aluvionares. Ainda segundo Chaves (1997), as amostras provenientes das partes altas da Serra do Espinhaço (Córrego do Capão e Ribeirão do Inferno) indicaram valores muito semelhantes com aqueles apresentados para as granadas do Rio Jequitinhonha, a leste da serra. Assim sendo, a almandina comum nos depósitos aluvionares deste último rio provavelmente procede de granitóides do Embasamento pré-Espinhaço, como as que ocorrem na região de Gouveia e adjacências, onde o Córrego do Capão e o Ribeirão do Inferno possuem as suas nascentes. 
CARACTERÍSTICAS FÍSICAS DO DIAMANTE DO ESPINHACO Peso e granulometria Para a determinação da distribuição de peso e granulometria do diamante nas diversas áreas pesquisadas, considerou-se não só os lotes estudados em detalhe, como também outros lotes observados só para este fim, em posse de comerciantes de diamantes das localidades envolvidas. A Figura 2 mostra os histogramas da distribuição das percentagens por peso, até $1,60 \mathrm{ct}$ Acima deste peso, as percentagens foram sempre muito baixas $(<0,5 \%)$ para serem representadas. Diversas características são comuns a todas as áreas, como por exemplo, os raríssimos cristais pesando mais que 5 ct, provavelmente ocorrendo na proporção de 1 para cada 100.000 (significando algo como $0,1 \%$ em peso). O peso médio do diamante nas áreas pesquisadas é sempre inferior a 0,5 et: Datas - 0,35 ct; Grão Mogol - 0,11 ct; Serra do Cabral -0,42 et.

No Rio Jequitinhonha obteve-se uma média de peso através do estudo de lotes "completos" de áreas de dragagem da Mineração Rio Novo, a qual não diferenciou do padrão geral: 0,20 et obtidos em cerca de 20.000 cristais. Esses dados estão também de acordo com Haraly \& Svisero (1986), que verificaram uma mediana da ordem de 0,26 ct em Extração (Lavra Boa Vista). O Distrito de Grão Mogol caracterizase por possuir o maior percentual de cristais com peso inferior a 0,2 et $(49 \%)$ e também por apresentar uma proporção pouco significante $(<0,5 \%)$ de pedras com mais que $1,2 \mathrm{ct}$, dados estes assinalados desde longa data (Helmreichen 1846). As demais áreas (Datas, Rio Jequitinhonha e Serra do Cabral) apresentaram valores semelhantes de pedras maiores que 1,0 ct $(7-10 \%$ de peso), assim como nas proporcões relativas de cristais pesando entre $0,2-1,0 \mathrm{ct}$. A aparente "anomalia" de cristais com peso inferior a 0,2 ct na área do Rio Jequitinhonha (42\% em peso) é explicável pelo processo de lavra altamente mecanizado (Mineração Rio Novo), que obtém uma ótima recuperação dos diamantes $(=95 \%)$, ao contrário do que ocorre em Datas e Jequitaí, onde a extração é feita por garimpagem, com rendimento bastante inferior Destaca-se ainda a existência de cristais muito pequenos na região, com hábito perfeito. No Distrito de Diamantina, foram determinados dois desses microcristais na fração de minerais pesados, em amostras das lavras Serrinha (0,003 ct) e Datas de Cima (0,004 ct). Da mesma forma, no Distrito de Grão Mogol foi amostrado na Serra da Pedra Rica um microcristal pesando $0,006 \mathrm{ct}$.

$\mathrm{Na}$ Tabela 1, os grandes diamantes reportados para a região do Espinhaço são comparados aos maiores que se tem notícia em outras zonas diamantíferas de Minas Gerais. Sobre as demais regiões produtoras brasileiras, os dados são muito escassos. Ressalta-se a forte discrepância entre os cristais de maior peso do Espinhaço com os de outras áreas. Barbosa (1991) cita a existência de alguns grandes achados no Distrito de Diamantina. Todos esses, porém, ocorreram na época da "Real Extração" (1770-1842) quando a produção desta região era misturada com a do Rio Abaeté, a oeste do Rio São Francisco, onde a existência de grandes diamantes é comum, e por isso não foram considerados na tabela.
Morf ologia O Barão von Eschwege, na obra clássica Pluto Brasiliensis, descreveu pela primeira vez os hábitos cristalográficos e outras feições de cerca de 100 diamantes brasileiros, a maioria provavelmente oriunda do Distrito de Diamantina (Eschwege 1833). Fersman \& Goldschmidt (1911) detalharam as formas de dezenas de cristais, diversos deles pertencentes à região abrangida no presente estudo. Em termos sistemáticos, Harris et al. $(1975,1979)$ efetuaram estatísticas envolvendo os principais aspectos morfológicos do diamante, com base em pçpulações representativas lavradas de alguns pipes kimberlíticos da Africa do Sul. Nesses trabalhos demonstrou-se que diversos aspectos mineralógicos do diamante são particulares e diagnósticos de cada um dos depósitos. Na classificação estatística de grandes populações, essa sistematização mostrou-se prática e também utilizada por Svisero \& Haralyi (1985) no estudo do diamante da Mina de Romaria, região do Alto Paranaíba, sendo acompanhada no presente trabalho.

A respeito das transições entre o hábito octaédrico de faces planas e arestas retilíneas para o rombododecaédrico de faces abauladas e arestas curvas, certas considerações devem ser levadas em conta, uma vez que constituem um ponto de divergência entre os diversos sistemas classificatórios encontrados na literatura (p. ex., Orlov 1973, Harris et ai. 1975,1979, Svisero \& Haralyi 1985). Por não apresentarem reflexões definidas, os cristais de faces curvas não podem ser estudados quanto às suas relações goniométricas, tornando subjetiva a caracterização morfológica nesses casos. Considerando assim que o octaedro sofre dissolução ao longo de suas arestas e em conseqüência surjam superfícies correspondentes ao rombododecaedro, torna-se difícil classificar o cristal resultante desses processos. No presente estudo, os estágios transicionais entre os dois hábitos foram simplificadamente designados de "octa-dodecaedros".

Conforme a tabela classificatória (Chaves 1997), adotou-se um esquema geral envolvendo os tipos monocristalinos e os policristalinos. Entre os primeiros, foram definidas formas simples, como cubo, octaedro, rombododecaedro, octa-dodecaedro, etc.; combinadas; geminadas; agregadas; irregulares; e fragmentos de clivagem. Se o cristal mostrou mais que $50 \%$ de um hábito específico, ele foi considerado como pertencendo à divisão classificatória correspondente; porém se exibiu menos que $50 \%$ de um determinado hábito, ele foi designado como irregular ou fragmento de clivagem, conforme o caso. As formas policristalinas foram divididas em agregados policristalinos complexos (borts); bailas; e carbonados. Na apresentação dos resultados, a aproximação das porcentagens para duas casas decimais fez-se necessária para poderem ser caracterizados os tipos presentes em quantidades ínfimas, ao exemplo das variedades policristalinas. Diversas conclusões podem ser tiradas a respeito da Tabela II. Os hábitos simples, como o octaedro e o rombododecaedro (incluindo as transições entre ambos e o trioctaedro), constituem na região da Sefra do Espinhaço a maior parte dos cristais estudados, variando entre $73-77 \%$. Os outros hábitos simples como o cubo e o tetrahexaedro são raríssimos no Espinhaço, em comparação com as localidades do Alto Paranaíba.
(A) Datas $-191,17 \mathrm{ct}$

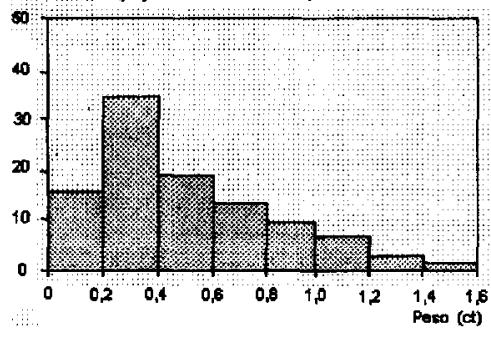

(B) Rio Jequitinhonha - $1938,46 \mathrm{ct}$

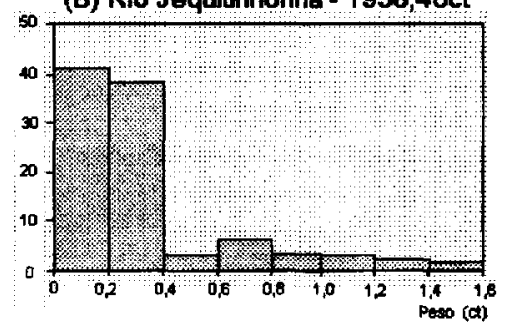

(C) Grab Mogol - 42,24ct

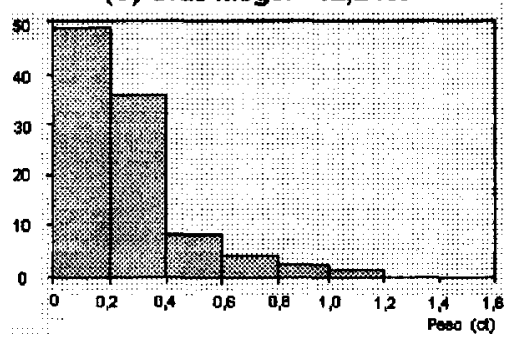

(D) Jequitai - 131,36ct

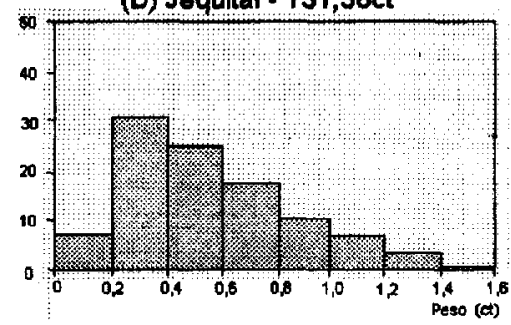

Figura 2 - Histogramas da distribuição do peso dos diamantes nas áreas de Datas (A), Rio Jequitinhonha (B), Grão Mogol (C) e Serra do Cabral (D). 
Tabela 1 - Os grandes diamantes reportados para a região da Serra do Espinhaço, em comparação com outros análogos extraídos em diversas zonas diamantíferas de Minas Gerais. Fontes bibliográficas em sobrescrito, (a) Chaves \& Uhlein 1991, (b) Haralyi et al 1991, (c) Helmreichen 1846, (d) Barbosa 1991, (e) Chaves 1997.

\begin{tabular}{|c|c|c|c|c|c|c|c|}
\hline \multicolumn{2}{|c|}{ REGIAOROCAL } & \multicolumn{6}{|c|}{$\begin{array}{l}\text { MAIORES DIAMANTES I ANO DE DESCOBERTA } \\
\rightarrow \text { (Ordem decrescente de grundeza, en qullates) } \rightarrow\end{array}$} \\
\hline ESPINHAÇO & $\begin{array}{c}\text { Diamaatina } \\
\text { Gräo Mogol } \\
\text { Serra do } \\
\text { Cabral }\end{array}$ & $\begin{array}{l}64,4 \text { (a) } \\
(1954) \\
30,5 \text { (c) } \\
(1840) \\
22,5 \text { (e) } \\
(1972)\end{array}$ & $\begin{array}{l}58,0 \text { (b) } \\
(1974) \\
16,0(\mathrm{c}) \\
(1940) \\
16,5(\mathrm{c}) \\
(1955)\end{array}$ & $\begin{array}{l}54,0(\mathrm{~b}) \\
(1963-4) \\
13,0(\mathrm{e}) \\
(1968) \\
9,5(\mathrm{c}) \\
(1983)\end{array}$ & $\begin{array}{l}49,8 \text { (b) } \\
(1935) \\
6,0(\mathrm{e}) \\
(1979) \\
9,2(\mathrm{c}) \\
(1994)\end{array}$ & $\begin{array}{l}38,0(\mathrm{~b}) \\
(1935) \\
5,5(\mathrm{e}) \\
(1988) \\
9,0(\mathrm{e}) \\
(1971)\end{array}$ & $\begin{array}{l}37,5(\mathrm{~b}) \\
(1974) \\
4,5(\mathrm{e}) \\
(1993) \\
6,7(\mathrm{c}) \\
(1980)\end{array}$ \\
\hline $\begin{array}{l}\text { ALTO } \\
\text { PARANAfBA }\end{array}$ & $\begin{array}{c}\text { Estrela do Sul } \\
\text { Romaria } \\
\text { Abadia dos } \\
\text { Dourados } \\
\end{array}$ & $\begin{array}{c}726,7 \text { (d) } \\
(1938) \\
254,5 \text { (d) } \\
(1853) \\
195,0 \text { (d) } \\
(1925)\end{array}$ & $\begin{array}{c}602,0^{\text {(c) }} \\
(1994) \\
179,5 \text { (d) } \\
(1909) \\
180,0 \text { (d) } \\
(1934)\end{array}$ & $\begin{array}{c}460,0^{(\mathrm{d})} \\
(1939) \\
174,5 \text { (d) } \\
(1954) \\
176,0^{(\mathrm{d})} \\
(1947)\end{array}$ & $\begin{array}{c}428,0 \text { (d) } \\
(1940) \\
170,0 \text { (d) } \\
(1994) \\
104,0^{\text {(d) }} \\
(1938)\end{array}$ & $\begin{array}{l}400,5 \text { (d) } \\
(1940) \\
122,5 \text { (d) } \\
(1857) \\
91,0 \text { (d) } \\
(1940)\end{array}$ & $\begin{array}{c}375,0^{\text {(d) }} \\
(1941) \\
118,0^{\text {(d) }} \\
(1929) \\
90,0^{\text {(d) }} \\
(1940)\end{array}$ \\
\hline $\begin{array}{l}\text { OESTE SÁO } \\
\text { FRANCISCO }\end{array}$ & Rio Abacá & $\begin{array}{c}354,0 \text { (d) } \\
(1938)\end{array}$ & $\begin{array}{c}198,0 \text { (d) } \\
(1936)\end{array}$ & $\begin{array}{l}182,0 \text { (d) } \\
(1936-7)\end{array}$ & $\begin{array}{l}173,0^{(d)} \\
(1938)\end{array}$ & $\begin{array}{l}165.5 \text { (d) } \\
(1739)\end{array}$ & $\begin{array}{l}144,0^{(d)} \\
(1798)\end{array}$ \\
\hline
\end{tabular}

Outra característica marcante é a baixa freqüência de fragmentos de clivagem $(3,9-7,2 \%)$ e de agregados policristalinos $(<0,5 \%)$ entre os diamantes do Espinhaço.

Figuras de superfície $O$ estudo das estruturas presentes nas superfícies de diamantes procedentes das várias áreas pesquisadas foi realizado através de microscopia óptica e eletrônica, permitindo obter uma série de dados relativos ao microrelevo e processos relacionados à morfologia externa dos cristais. Patel \& Agarwal (1965) observaram que a velocidade de dissolução na superfície do diamante não era homogênea, ocorrendo seletivamente na seguinte ordem dos planos cristalográficos: $(110)>(100)>\left(\begin{array}{lll}1 & 1 & 1\end{array}\right)$, ou seja, existe uma diferença relativa na velocidade de dissolução entre esses planos que facilita a corrosão segundo (110), correspondente às faces do rombododecaedro. Este fato explica porque os cristais, inicialmente octaédricos, tornamse progressivamente rombododecaédricos.

MICROESTRUTURAS EM (111) As faces (111) do diamante são as únicas com superfícies planas, geralmente lisas, contendo estruturas simétricas ao eixo ternário. As arestas variam desde agudas até muito arredondadas. Os trígonos (trigons) representam as principais figuras observadas nestas faces, constituindo depressões triangulares equiláteras de profundidades variáveis, podendo ser notadas desde a vista desarmada até dimensões próximas a $10 \AA$ (Leite 1969). Essas feições orientam-se em oposição ao contorno triangular das faces do octaedro e o fundo das depressões pode ser plano ou escalonado. Entre os diamantes do Espinhaço os trígonos são muito raros a nível macroscópico, tendo sido observados em apenas 13 cristais dos 1773 examinados no campo. $\mathrm{O}$ aspecto liso das faces (111), contrasta com o aspecto "áspero" que em geral as faces do rombododecaedro apresentam, e isto fica evidente nos cristais transicionais entre os dois hábitos, onde ambas as características podem ser notadas.

MICROESTRUTURAS EM (100) Nas faces de cubo, raramente observadas nos cristais examinados, ocorrem sempre figuras características com a forma de cavidades de contorno quadrado ou retangular, escalonadas ou piramidais. Essas cavidades são pouco profundas e se encontram inclinadas a $45^{\circ}$ das arestas cúbicas. Williams (1932) interpretou tais estruturas como originadas pelo crescimento cristalino. De outra maneira, Leite (1969) considerou improváveis quaisquer figuras de crescimento na superfície de diamantes naturais, preferindo explicá-las por processos corrosivos diversos. Certos hábitos semelhantes a hexatetraedros tabulares, presentes principalmente entre os diamantes da região de Grão Mogol, foram interpretados como o produto da corrosão sobre as faces do cubo. Nas descrições de campo, esses cristais foram classificados como irregulares.

MICROESTRUTURAS EM (110) Fersman \& Goldschmidt (1911) postularam ser as faces (110) resultantes de processos naturais de dissolução. Entre os diamantes sul-africanos, Williams (1932) realçou a presença comum de estrias paralelas sobre essas faces. Moore \& Lang (1974) examinaram com detalhe as feições típicas de arredondamento quase sempre presentes nestas superficies. De particular importância, as estruturas em "degraus escalonados" presentes caracterizam-se por apresentar um padrão geométrico constante, que podem ser observadas desde pequenos aumentos até ampliações de centenas de vezes. Cada degrau corresponde a um plano (111) formado durante o crescimento do cristal. A dissolução atua nos setores de separação dos sucessivos planos e produz inicialmente um abaulamento nas bordas dos degraus
Tabela 2 - Caracterização morfológica do diamante da Serra do Espinhaço (dados de \% em relação ao número de cristais examinados), comparada com dados da mesma ordem reportados para a região do Alto Paranaíba (Mina de Romaria - Svisero \& Haralyi 1985, Triângulo Mineiro - Leite 1969). Os dados do Distrito de Diamantina foram obtidos pela média aritmética ponderada das percentagens das áreas de Datas e Rio Jequitinhonha.

\begin{tabular}{|c|c|c|c|c|c|}
\hline \multirow{2}{*}{$\begin{array}{l}\text { LOCAL } \\
\left(n=n^{\circ} \text { de cristais }\right) \\
\text { HÁBITOS (\%) }\end{array}$} & \multicolumn{3}{|c|}{ SERRA DO ESPINHAÇO } & \multicolumn{2}{|c|}{ ALTO PARANAIBA } \\
\hline & 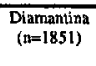 & $\begin{array}{c}\text { Orâu Mogol } \\
(n=768)\end{array}$ & $\begin{array}{c}\text { Serra do Cabral } \\
(11=408)\end{array}$ & $\begin{array}{l}\text { Mina de de } \\
\text { Romania } \\
(n=5317)\end{array}$ & $\begin{array}{l}\text { Triânguto } \\
\text { Mincio } \\
\text { Mn=230) }\end{array}$ \\
\hline 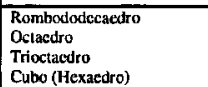 & $\begin{array}{l}34,3 \\
16.9 \\
1.0 \\
0.1\end{array}$ & $\begin{array}{l}33,6 \\
21,6 \\
0.1 \\
0.1\end{array}$ & $\begin{array}{l}38,5 \\
25,5 \\
0.5\end{array}$ & $\begin{array}{c}29,0 \\
5,2 \\
-2 \\
8,1\end{array}$ & $\begin{array}{l}28.3 \\
15.7 \\
.0 .9\end{array}$ \\
\hline 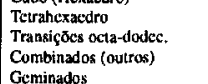 & $\begin{array}{c}22,3 \\
0.44 \\
8,1\end{array}$ & $\begin{array}{l}17,7 \\
0.5 \\
9,8\end{array}$ & 23.3 & $\begin{array}{l}2,4 \\
6,9\end{array}$ & $\begin{array}{l}7,8 \\
2,2 \\
13.8\end{array}$ \\
\hline 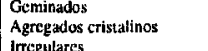 & 0,1 & & 0.2 & & \\
\hline 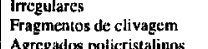 & 7,2 & 7,2 & 3,9 & 24,2 & 12,0 \\
\hline $\begin{array}{l}\text { Agrcrgades poticristalinos } \\
\text { Ballus } \\
\text { Carbondor }\end{array}$ & $\begin{array}{l}0,1 \\
0.1\end{array}$ & 0,5 & 0,2 & & \\
\hline
\end{tabular}

(Svisero 1969). As regiões contendo menor número de defeitos cristalinos oferecem uma resistência maior à dissolução, destacando-se na superfície. Esses detalhes constituem evidências diretas de que tais feições sejam produzidas pela dissolução natural.

Um dos principais problemas concernentes às superfícies $\left(\begin{array}{lll}1 & 1 & 0\end{array}\right)$ é a presença comum de certas figuras com formas aproximadas de meialua, comercialmente designadas como "unhadas". Essas figuras são conhecidas no âmbito da geologia como impact marks (Censier \& Tourenq 1995) e, como o nome define, seriam produzidas durante o transporte do diamante no meio fluvial. Ensejando contribuir para o esclarecimento de tal questão, essas estruturas foram examinadas em detalhe, porém não se encontrou nenhuma evidência adicional a favor dessa hipótese. As citadas estruturas foram observadas apenas em faces do rombododecaedro. Se elas resultassem do transporte, deveriam estar presentes indistintamente em todos os tipos de faces cristalinas. Sob a observação no microscópio, essas feições adquirem contorno geométrico regular, muitas vezes semelhantes às estruturas em degraus descritas por Svisero $(1969,1971)$. O contorno escalonado e repetido de certas depressões tidas como de impacto, favorece a hipótese de que elas sejam produto de dissolução natural. Esses dados estão de acordo com Svisero (1971), que ressaltou: "a clivagem é a única alteração sofrida pelo diamante durante o transporte".

Inclusões Existem poucos estudos sobre as inclusões minerais em diamantes do Espinhaço. Guimarães (1934) mencionou a existência de inclusões de quartzo nos diamantes da região de Diamantina, atualmente consideradas como inclusões epigenéticas, onde o quartzo aparece preenchendo microfraturas no cristal hospedeiro (Meyer \& Svisero 1975). Posteriormente, em diamantes do Rio Jequitinhonha, foram determinados com microssonda eletrônica cromo-espinélio, enstatita e forsterita (Svisero 1978). Haralyi et al. (1991) descrevem a presença de olivina e granada inclusas nesses diamantes.

A Tabela III mostra os dados sobre as inclusões em geral, nos diamantes das diversas áreas estudadas. Esses dados revelam que as inclusões são raras, sendo o percentual dos diamantes "limpos" sempre superior a $60 \%$. A classe designada "diamantes opacos" inclui os exemplares onde não é possível observar a presença de inclusões, tais como nos cristais cúbicos e também nas variedades policristalinas. Entre as inclusões presentes, mais que $95 \%$ constituem os "carvões" e "urubus" no âmbito comercial. O estudo dessas inclusões no microscópio óptico revelou que na maioria dos casos essas feições podem ser consideradas como fraturas internas enegrecidas. Portanto, estudos adicionais são necessários para esclarecer a composição química dos demais "carvões" que constituem inclusões minerais verdadeiras. Outras inclusões minerais presentes, observadas pelo mesmo método, incluem provável olivina, granada e cromita.

Variedades policristalinas Entre as variedades em que o diamante é encontrado, é comum ocorrerem microcristais agregados, densamente compactados, podendo ou não mostrar alguma forma definida. Observa-se na literatura uma certa imprecisão entre os tipos mineralogicamente definidos e os conceitos puramente comerciais. Williams (1932) agrupou como "agregados cristalinos" sete destas variedades, algumas nunca descritas em depósitos brasileiros: bort, bailas, framesite, stewartite, short bort, hailstone bort e carbonado, embora outros autores como Orlov (1973) e Gaal (1977) considerem 
Tabela 3 - Freqüência da presença de inclusões, não discriminadas, em diamantes da Serra do Espinhaço (dados de percentagem em relação ao número de cristais examinados, $=n$ ).

\begin{tabular}{|c|c|c|c|c|}
\hline $\begin{array}{l}\text { AREA } \\
\text { (n=número de cristais) } \\
\text { INCLUSŌES }\end{array}$ & $\begin{array}{l}\text { DATAS } \\
(n=597)\end{array}$ & $\begin{array}{c}\text { RIO } \\
\text { JEQUITINHONHA } \\
(n=1254)\end{array}$ & $\begin{array}{c}\text { GRAO MOGOL } \\
(n=768)\end{array}$ & $\begin{array}{c}\text { JEQUITAI } \\
\text { (n=408) }\end{array}$ \\
\hline Sem inclusōes & 68,17 & 78,63 & 60,42 & 77,21 \\
\hline Visíveis com lupa 10X & 18,76 & 11,32 & 20,57 & 16,91 \\
\hline Visíveis a olho-nú & 13,06 & 9,89 & 18.36 & 5,88 \\
\hline Cristais opacos & & 0,16 & 0.65 & \\
\hline
\end{tabular}

que alguns destes termos são apenas subtipos da variedade bort. De outra maneira, o Departamento Nacional da Produção Mineral classifica o bort como toda a produção de "fundo", isto é, da qualidade mais inferior em termos industriais, desconsiderando assim se o bort é mono ou policristalino. No presente estudo, reconheceu-se as divisões: agregados policristalinos complexos (bons), bailas e carbonado, cujos conceitos são característicos em termos mineralógicos e que estão presentes nos depósitos da Serra do Espinhaço. Além disso, essas formas têm sido previamente agrupadas por Moriyoshi et al. (1983) baseando-se em suas propriedades estruturais microcristalinas.

AGREGADOS POLJCRISTALINOS COMPLEXOS Sob essa definição, são aqui considerados os agregados de diamantes com aspecto irregular, não possuindo os cristalitos hábitos determináveis e onde normalmente o número de indivíduos presentes é sempre superior a algumas dezenas. Na realidade esta conceituação reúne os tipos bort, muito comuns em determinados depósitos brasileiros, como Juína (Mato Grosso), e presentes também, embora em menor proporção, entre os diamantes de Coromandel e do Rio Abaeté (Chaves 1997). Os agregados policristalinos deste tipo são raríssimos entre os diamantes do Espinhaço. Agregados complexos realmente comparáveis ao bort somente foram verificados na região de Grão Mogol, onde se observou três exemplares dessa variedade (Tab. II), o maior deles pesando 0,21 et. Foram notados raros agregados de dois ou três cristais nas áreas do Rio Jequitinhonha e de Jequitaí, porém, os indivíduos possuíam formas definidas representando o intercrescimento de hábitos monocristalinos, sendo classificados como agregados cristalinos.

BALLAS Diamantes bailas são definidos como agregados policristalinos de desenvolvimento orientado globular, nos quais os cristalitos apresentam direções (110) radiais, resultando em uma forma esférica ou próxima dela (Moriyoshi et al. 1983), normalmente de coloração leitosa branca ou levemente acinzentada. Esses diamantes podem ser considerados incomuns, mas é interessante ressaltar que eles estão presentes em todos os depósitos estudados. Em Grão Mogol foram descritos dois diamantes bailas, enquanto nas demais áreas foi notada a presença de apenas um, determinando assim os baixos percentuais verificados (Tab. II). No Rio Jequitinhonha, apesar de não ter sido examinado nenhum diamante deste tipo nos lotes da Mineração Rio Novo, foi descrito um exemplar pesando 13,7 et, perfeitamente esférico, durante os trabalhos de campo em um garimpo semi-mecanizado a jusante no mesmo rio, e que por suas características realmente notáveis foi incorporado ao conjunto descrito. No Distrito da Serra do Cabral, apesar do menor número de cristais examinados, foi descrito um bailas com 0,32 et. Os comerciantes de diamantes entrevistados em Jequitaí, porém, consideram esta forma como raríssima na localidade. No Campo de Datas, acredita-se que o valor próximo de $0,2 \%$ seja bem realístico (também baseado em entrevistas com comerciantes locais), e o único exemplar estudado pesou 0,37 et.

CARBONADO Sob a designação de carbonados os mineradores brasileiros definem desde longa data esta variedade policristalina singular, atualmente reconhecida em toda a literatura mineralógica, como um agregado mais ou menos poroso e de aspecto irregular de microcristais com tamanhos muito reduzidos (da ordem de IO- ${ }^{2}$ a $10 \sim^{3}$ mm, segundo Orlov 1973). Sua coloração é preta, possuindo tonalidades acinzentadas e pardacentas, evidenciando uma grande quantidade de impurezas. O Brasil é o maior produtor mundial de carbonados, cuja principal área fornecedora é a Chapada Diamantina (BA), onde $10-20 \%$ do total da produção diamantífera é compreendida por esta variedade (Schobbenhaus 1993). Provavelmente a segunda área mais importante na produção de carbonados está no Médio Jequitinhonha, (Espinhaço Central), a jusante da confluência com o Rio Macaúbas.

Nesta última região, verificou-se em todos os garimpos uma produção regular e constante de carbonados, variável sempre entre 1-2\% em peso do total de diamantes extraídos. A montante desta área, porém, incluindo assim todo o Distrito de Diamantina, esta variedade não ocorre. Esses dados, assinalados desde longa data (Moraes \& Guimarães 1930, Moraes 1934), são confirmados por mais de 20 anos de producão mecanizada no Rio Jequitinhonha pelas mineradoras Tejucana (H. Dupont 1991, comunicação verbal) e Rio Novo (R. Fleischer 1993, comunicação verbal). Na região serrana de Grão Mogol, os carbonados são raros mas conhecidos pela maioria dos garimpeiros, sendo examinado um espécime com 0,61 et procedente da Serra da Pedra Rica, a nordeste da cidade. A presença desta variedade no local, onde ocorrem conglomerados diamantíferos da Formação Grão Mogol (Chaves et al. 1997), não parece deixar dúvidas de que tais rochas sejam a fonte secundária tanto dos diamantes monocristalinos como dos carbonados na região.

Uma assembléia variada e complexa de inclusões tem levado muitos autores à consideração de que os carbonados possuem uma origem crustal (p. ex., Kaminski 1994, Shibata et al 1993). Esses autores, porém, não explicaram porque os carbonados ocorrem juntamente com diamantes monocristalinos em todas as áreas onde são descritos. Além disso, tanto no Espinhaço Central (Distrito de Grão Mogol) como na Chapada Diamantina, diamantes e carbonados são derivados de conglomerados proterozóicos, indicando que ambos foram espalhados na mesma época, durante a sedimentação do Supergrupo Espinhaço, provavelmente a partir de uma fonte similar.

Caracterização gemológica Até o final do século passado, o interesse pelo diamante era apenas para o adorno pessoal, daí a famosa expressão de Henry Gorceix que a ele se referia como "a mais preciosa das inutilidades". A partir do século 20, o diamante passou a ter uma ampla utilização industrial por suas características físicas únicas. Desde então, a divergência entre conceitos acadêmicos e comerciais, determinou a criação de uma terminologia e classificação próprias no sentido de descrever as feições de cor e impurezas presentes em diamantes gemológicos. Nos cristais examinados, foi estabelecida uma padronização gemológica quanto à cor baseada na escala do Gemological Institute of America (GIA). No campo, utilizou-se uma escala padrão classificada pelo GIA (cinco pedras em zircônia), com as cores "E", "G", "I", "K", "M". Várias simplificações foram porém introduzidas (Tab. IV): col-1, branco extra (equivalente às cores "D", "E", "F", "G"); col-2, branco "comercial" (cores "H", "I"); col-3, branco levemente amarelado (cores "J", "K", "L"); col-4, branco amarelado (cores "M", "N"..."Z"); col-5, cores de fantasia (fancy colors'), como amarelocanário, laranja, rosa e azul; col-6, qualquer cor relativa aos diamantes que não se enquadram como gemas. Os grupos de cores aqui designados de col-1, col-2, col-3 e col-4 são os mais freqüentes nos diamantes naturais.

Da mesma forma, com relação à pureza, certas simplificações foram introduzidas em relação à escala do GIA (Tab. IV): pur-1, sem inclusões e jacas (equivalente aos graus "IF"e "WS"); pur-2, com inclusões muito pequenas, vistas só com lupa de 10 aumentos ("VS", "SI"); pur-3, com inclusões e/ou jacas pequenas visíveis a olho nu ("I $\left.I_{1} "\right)$; pur-4, com inclusões e/ou jacas médias e grandes ("I $\mathrm{I}_{2}$, " $\left.\mathrm{I}_{3} "\right)$; pur-5, borts, bailas e cristais com muitas inclusões, jacas, etc., que não se enquadram como gemológicos, não possuindo assim equivalentes na escala do GIA.

Nas áreas de Datas, Grão Mogol e Jequitaí, o estudo preferenciou lotes inteiros da produção semanal de diamantes, e os dados obtidos entre vários lotes foram depois recalculados pela média aritmética ponderada. Esta precaução é necessária porque muitas vezes os compradores podem estocar, com finalidade especulativa, um determinado tipo de qualidade comercial entre os seus lotes particulares. $\mathrm{Na}$ área do Rio Jequitinhonha, foram examinados dois lotes da área lavrada pela Mineração Rio Novo, onde, segundo informação do seu diretor comercial em 1994 (Sr. Antônio Tomaz), a produção dos últimos 10 anos de operação não mostrou diferenças significativas quanto a seus valores de comércio. Isto indica não haver modificações em termos de qualidade gemológica do diamante e que os lotes estudados são plenamente representativos para a área.

Os dados em relação ao detalhamento das escalas adotadas de coloração e de pureza são também mostrados na Tabela 4. Observa-se que a coloração predominante entre os diamantes gemológicos varia entre o branco levemente amarelado até o branco amarelado. Esses dados estão de acordo com a opinião dos principais diamantários de Diamantina, de que a "média" das cores dos diamantes da região varia entre "I" e "J" (V. Siao 1994, comunicação verbal). Da mesma forma, os dados quanto a pureza do diamante revelam que em todas as áreas predominam $(>60 \%)$ diamantes com pureza 1 e 2 da classificação ora adotada. 
Assim, os dados da Tabela 4 demonstram que a relação gema/indústria dos diamantes do Espinhaço varia entre $78 \%$ em Grão Mogol e 97,1\% em Jequitaí, representando em escala mundial um dos mais elevados índices (Karfunkel et al. 1996, Fig. 3). E interessante observar que os diamantes qualificados comercialmente como fundo (borts) não ultrapassam $2 \%$ nos lotes examinados, mesmo incluindo entre estes a variedade bailas.

\section{DISCUSSÃO SOBRE A ORIGEM DO DIAMANTE DO}

ESPINHAÇO O diamante do Espinhaço envolve três períodos principais no tempo geológico, com relação à sua origem e às suas sucessivas distribuições sofridas no tempo e no espaço:

(i) um período magmático de idade pré-cambriana, a respeito do qual não existe nenhum vestígio documentado, exceto os diamantes;

(ii) um longo período de redistribuição ainda no Pré-Cambriano, onde o diamante foi trabalhado no meio fluvial e em leques aluviais dentro da bacia do Espinhaço, o qual apresenta evidências escassas;

iii) um novo período de redistribuição desde o Eocretáceo, nos domínios da Serra do Espinhaço e nos seus sistemas de paleodrenagens para leste (bacia do Rio Jequitinhonha) e para oeste (bacia do Rio São Francisco), com amplo documentário geológico disponível, tendo sido objeto de recentes trabalhos de Karfunkel \& Chaves (1995) e Chaves \& Karfunkel (1997).

Mineralogia e redistribuição do diamante Apesar da rocha fonte do diamante não ser conhecida, o período subsequente de redistribuição do mineral no meio aluvial é da máxima importância. Para o seu conhecimento, procurou-se delinear uma comparação com certos modelos envolvendo o espalhamento dos diamantes neste meio, propostos para algumas províncias diamantíferas conhecidas. Nos kimberlitos e lamproítos os teores médios do mineral verificados em dezenas de intrusões variam preferencialmente entre 1-3 ct $/ \mathrm{m}^{3}$ (Helmstaedt 1993, Janse 1993). Os estudos efetuados por Sutherland (1982) demonstraram a sistemática variação no tamanho e na classificação dos diamantes a partir de suas fontes, como resultado do transporte fluvial e marinho. Baseado em depósitos do oeste (Serra Leoa) e centro da Africa (Zaire e Angola), este autor constatou que diamantes originados de áreas fontes restritas foram espalhados por milhares de quilômetros quadrados, verificando-se uma sistemática redução na média do tamanho dos cristais com o aumento da distância de transporte. Tal redução no tamanho, porém, foi acompanhada pela melhoria gemológica dos diamantes, visto que os tipos de qualidade inferior são destruídos. Logo, o valor absoluto de lotes de diamantes provenientes de depósitos secundários representa um estado de equilíbrio entre o transporte (diminuição no tamanho/peso) e a qualificação gemológica (aumento da qualidade/preço médio).

Assim, certos hábitos como o cúbico e variedades como o bort são pulverizados durante o registro geológico, depois de reduzidos a partículas muito finas. Linari-Linholm (1973) mostrou em um experimento com moinho de bolas que somente 6 horas de moagem foram necessárias para reduzir o bort e pedras defeituosas de M'bugi-Mayi (Zaire) para menos que 60 mesh de tamanho, isto é, partículas com peso provavelmente inferior a 0,001 et. Com o mesmo procedimento, os diamantes da costa da Namíbia apresentando formas cristalinas, ou seja, os de qualidade gema, perderam apenas $0,01 \%$ de seu peso, depois de quase 1000 horas de moagem.

As proporções de fragmentos de clivagem também decrescem fortemente com o transporte. Assim, mais de $95 \%$ dos diamantes da região costeira sul-africana são compostos de formas cristalinas inteiras (Hallam 1964), e praticamente $100 \%$ das pedras podem ser consideradas como lapidáveis (cuttable) no sentido de Levinson et al. (1992). Além disso, deve ser destacado que os kimberlitos em geral possuem um altíssimo percentual de pedras clivadas (até $70 \%$, segundo Williams 1932) constituindo uma evidência adicional a favor do decréscimo de cristais deste tipo com o transporte. Os hábitos do diamante predominantes em kimberlitos e lamproítos são octaedros e rombododecaedros (Harris et al. 1975,1979, Hall \& Smith 1984). O transporte porém, preferencia a forma dodecaédrica. Como exemplo, os depósitos da Namíbia têm uma relação desproporcionalmente alta deste hábito (Sutherland 1982), que pode ser explicada pelo seu número superior de faces e pelo arredondamento destas causado pela dissolução, resultando em um coeficiente hidrodinâmico maior em relação aos outros hábitos.

Relacionando as principais modificações nas características físicas do diamante, ocorridas durante as diversas fases de transporte que o mineral sofre com a evolução do registro geológico (Chaves 1997): (i) o tamanho médio (e peso) dos cristais diminui; (ii) nos hábitos cristali- nos simples, existe uma modificação do predomínio do hábito octaédrico para o hábito rombododecaédrico; (iii) os fragmentos de clivagem diminuem expressivamente de proporção; (iv) borts e cristais com defeitos (incluindo os de hábito cúbico) e/ou muitas inclusões são progressivamente pulverizados; e (v) aumento da proporção dos cristais gemológicos (Fig. 3). Conforme os dados comparativos apresentados na Figura 3, a percentagem de diamantes gemológicos no Espinhaço (3A) é muito superior à dos diamantes encontrados em depósitos primários (3C) e comparável à dos depósitos secundários (3B), notadamente àqueles de mais longo transporte como os da Guiné e da Costa da Namíbia. A visão integrada desses dados e a comparação dos mesmos com os obtidos na caracterizacão física do diamante do Espinhaço (Fig. 2, Tabs. II, III e IV) são fortes argumentos apontando a favor de uma origem "distante", ou extra-bacia, para o mineral nesta região.

O aporte do diamante no Conglomerado Sopa No presente estudo procurou-se abranger a problemática da origem do diamante do Espinhaço, tendo como enfoque central sua caracterização mineralógica e os principais dados obtidos foram consoantes em relação à citada fonte extra-bacia (Tabs. I, II e III). Assim sendo, ficou ressaltada a insignificante proporcão de cristais de alto quilate, a larga predominância dos hábitos cristalinos simples, a raridade dos cristais defeituosos ou com inclusões, a virtual ausência de cubos e agregados policristalinos, e que a proporção de fragmentos de clivagem é desprezível em relação à de cristais "inteiros".

Os diamantes ballas constituem a única exceção relativamente importante de um tipo policristalino na região da Serra do Espinhaço, pois foram verificados em todas as localidades estudadas. A explicação para esta aparente anomalia é simples, uma vez que a forma esférica deste tipo facilita o seu transporte no meio fluvial e, por conseguinte, a sua preservação no registro geológico. O contrário acontece com os diamantes de hábito cúbico. Nestes, o reduzido número de faces associado a sua constituição interna com múltiplas microfraturas, fazem com que os cubos sejam facilmente eliminados no transporte. E ainda significativo realçar que os três microdiamantes encontrados durante o estudo não são fragmentos de clivagem, mas cristais inteiros, indicando que os fragmentos finos pulverizaram-se totalmente durante o processo geológico.

Essas características, comparadas com os dados mais recentes acerca dos diamantes de fonte secundária na África e na Austrália, indicam que a população de cristais encontrada nas várias áreas do Espinhaco é o resultado de sucessivos processos de transporte e deposição desde uma área longínqua. Como a área-fonte alimentadora da sedimentaç̃o da bacia do Espinhaço estava a oeste, onde se localiza o Cráton do São Francisco, nesta região deveriam estar presentes as rochas primárias do diamante, atualmente recobertas pelo Grupo Bambuí. $\mathrm{O}$ transporte do mineral desde essa região até os atuais sítios onde ele se encontra, selecionou certos hábitos cristalinos em relação a outros, aumentando assim a população de diamantes de qualidade gemológica (Tab. IV, Fig. 3).

Por outro lado, alguns argumentos mineralógicos a favor de uma origem próxima para esses diamantes, podem ser discutidos. O mais difundido deles se baseia no fato dos cristais normalmente apresentarem arestas angulosas (p. ex., Schölll \& Turinsky 1980, Herrgesell 1984). Entretanto, a única forma de desgaste que o diamante admite é a corrosão ocorrida durante o emplacement de sua rocha-fonte (Svisero 1971, Sutherland 1982). Chaves (1997) demonstrou em uma série de fotos com diamantes de diversas procedências, que o fato do cristal possuir arestas angulosas não tem qualquer relação com o transporte por ele sofrido. Assim sendo, em um lote de cristais da região de Diamantina, verificam-se cristais angulosos junto com outros arredondados. Da mesma forma, em cristais procedentes do Lamproíto Argyle (Austrália), também ocorrem associados cristais arredondados e não arredondados. Esse fato exemplifica que o grau de arredondamento apresentado pelo diamante deve-se unicamente à dissolução natural que atuou durante a colocação da rocha fonte.

Complementando a idéia de que o arredondamento dos diamantes não possui relação com o seu transporte, em dois cristais provenientes do placer costeiro da Namíbia, no sudoeste africano, se observam arestas agudas em cristais octaédricos. Esses cristais foram transportados no meio fluvial por cerca de $1000 \mathrm{~km}$ desde a sua área fonte no planalto sul-africano e ainda, em seqüência, foram carregados por correntes marinhas por mais de $100 \mathrm{~km}$ até serem sedimentados naquela região durante o Pleistocene. Mesmo assim, não apresentam qualquer evidência de desgaste mecânico. 
Tabela 4 - Principais características gemológicas quanto às cores e pureza do diamante da Serra do Espinhaço (dados de percentagem em relação ao peso da amostra, em quilates).
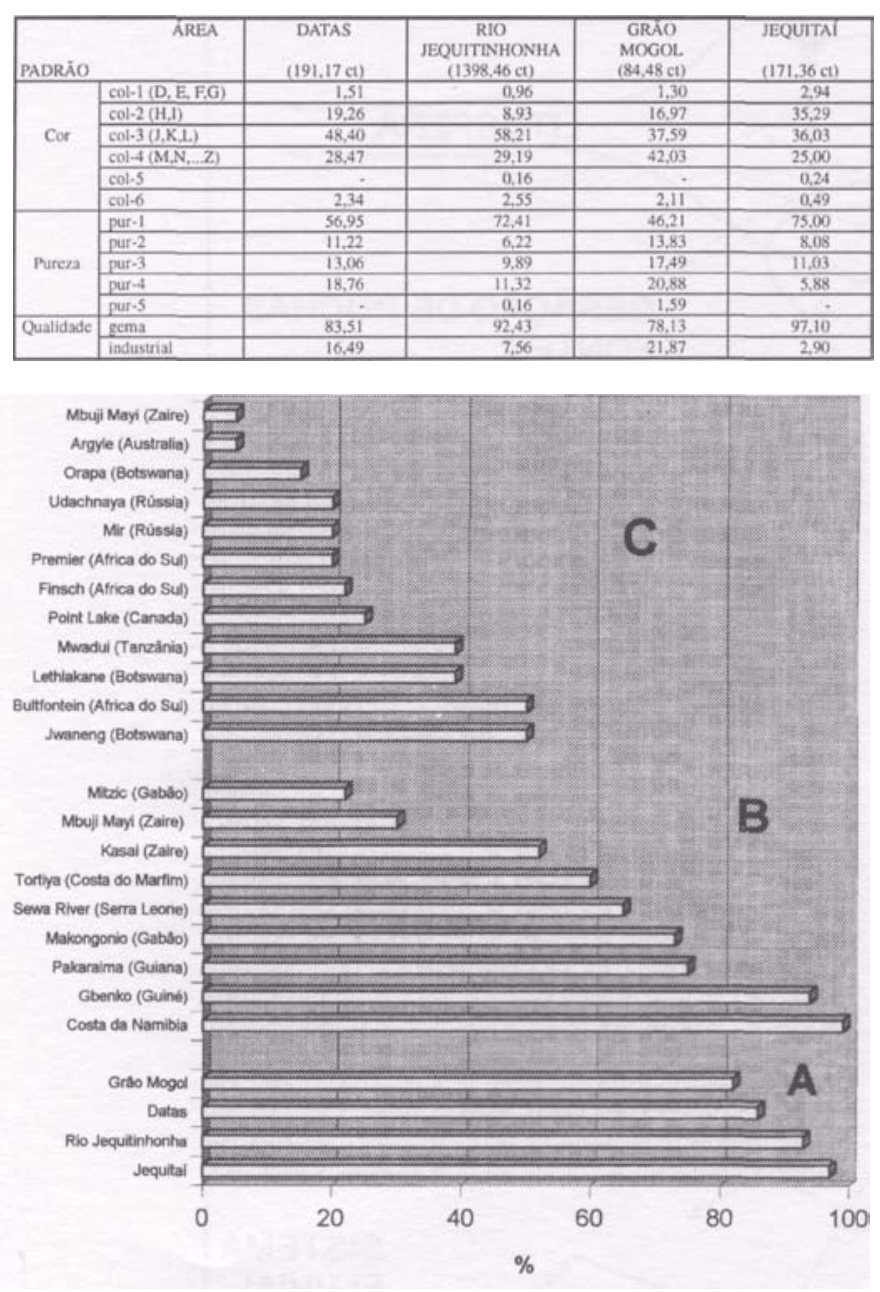

Figura 3 - Comparação das percentagens de diamantes gemológicos no Espinhaço com as de outras regiões do mundo (dados de Janse 1993, Karfunkel et al 1996). $A=$ Espinhaço, $B=$ Depósitos aluvionares, $C=$ Depósitos primários.

Um outro argumento normalmente aceito é o da suposta existência de populações características de diamantes em função de sua área de origem (Freyberg 1934, Herrgesell 1984, Almeida-Abreu 1996). Esta argumentação é também difundida entre certos diamantários de Diamantina, os quais dizem reconhecer a procedência das pedras que lhes são oferecidas. Os estudos efetuados nas diversas localidades, no entanto, não confirmaram esta consideração. Podem ocorrer aspectos característicos para diamantes de determinadas áreas, mas tais feições são inerentes às partes externas dos cristais. Assim sendo, observou-se que a maioria dos diamantes do Campo de São João da Chapada apresenta capa verde densa. Muitos cristais provenientes de Datas e Extração exibem um capeamento verde muito tênue em associação com um amarelamento causado por impregnação de óxidos. Essas feições foram adquiridas nos processos de sedimentação e/ou metamorfismo, portanto não possuem qualquer relação com os aspectos de ordens física e cristalográfica adquiridos na rocha fonte original, extensamente discutidos neste trabalho.

Segundo constatação geral dos pesquisadores que já atuaram na área, todos os depósitos conglomeráticos pertencentes à Formação Sopa Brumadinho na região de Diamantina são mineralizados, ou seja, fato independente de suas características locais. Em uma região tão extensa, havendo fontes primárias nas redondezas, deveriam ocorrer conglomerados diamantíferos e outros estéreis. Considerando-se ainda o imenso tamanho da província (Chaves 1997), deveriam existir milhares de "pontos" de rochas-fonte férteis, fossem elas kimberlíticas ou lamproíticas, para alimentarem de diamantes todos os conglomerados gerados nas suas adjacências.

Baseando-se nos argumentos apresentados anteriormente, os quais demonstraram que por seus aspectos mineralógicos o diamante tem sua origem relacionada a uma região externa à bacia, e ainda, considerando o Conglomerado Sopa e seus congêneres como possuindo uma origem relativamente próxima (p. ex., Garcia \& Uhlein 1987, Chaves \& Uhlein 1991, Almeida-Abreu 1993,1996) deve ser admitida a proposta de que certos depósitos conglomeráticos pretéritos também são diamantíferos. Esta possibilidade foi inicialmente levantada por Chaves et al. (1993) ao relatarem a existência de cursos d'água que não drenam a Formação Sopa Brumadinho mas que são diamantíferos. De maneira semelhante, Martins Neto (1993) considerou possível a ocorrência de diamantes nos conglomerados da Formação São João da Chapada (estratigraficamente inferior), ainda que este autor tenha relacionado sua fonte a intrusões na mesma formação. Em sentido mais amplo, deve ser destacado que os níveis de conglomerados que ocorrem nas unidades sedimentares pré-Sopa Brumadinho, nunca foram pesquisados para diamantes. Esses depósitos apresentam exposições regionais fragmentadas e de porte muito inferior às do Conglomerado Sopa.

O aporte do diamante nos conglomerados da Formação Sopa Brumadinho, por conseguinte, ocorreu a partir de conglomerados sedimentados preteritamente. Como a borda cratônica situava-se a mais que $100 \mathrm{~km}$ do núcleo inicial de abertura do rift, o diamante procedente desta área foi depositado dentro de um amplo sistema fluvial direcionado para o proto-njí. As unidades sedimentares das fases iniciais do rift não possuem diamantes ou o possuem em quantidades irrisórias, pois não recebiam contribuição sedimentar do citado sistema fluvial. Somente após o aporte dos sedimentos originados do cráton, o que ocorreu em seguida a um provável soerguimento da área fonte, os diamantes atingiram a zona de sedimentação do Espinhaço. Os conglomerados da Formação Sopa Brumadinho foram então redepositados principalmente na forma de leques aluviais.

\section{Argumentações para a origem distante do diamante A}

fonte do diamante na zona cratônica foi primeiramente proposta por Pflug (1965). No modelo geológico ora proposto, a partir de uma ou preferencialmente diversas localidades situadas no interior desta área, os diamantes foram distribuídos por extensa malha fluvial até se integrarem durante vários ciclos deposicionais ao sistema de rift que deu início a sedimentação do Supergrupo Espinhaço. Mitchell (1986, p. 122) é enfaticamente contrário à existência de kimberlitos nas próprias zonas de rifteamento: "there is little evidence to support the contention that kimberlites are related to rift structures. In all cases where this association has been proposed it can be demonstrated that the rocks in question are not kimberlites... or that rifts have been superimposed upon pre-existing provinces. This latter situation is rare and most kimberlites show no spatial or temporal relationship to rift valleys".

Em relação aos parâmetros de natureza mineralógica, estes são ainda mais evidentes em favor de uma origem longínqua para o diamante desta região. No estudo dos minerais pesados, verificou-se a ausência das principais fases minerais originadas de fontes kimberlíticas. Após extensa campanha prospectiva estes minerais não foram determinados nos conglomerados das formações Sopa Brumadinho e Grão Mogol, ou nos depósitos fanerozóicos derivados, embora microdiamantes tenham sido recuperados. Acredita-se que se houvessem fontes mineralizadas nas proximidades do sítio de sedimentação das formações Sopa Brumadinho e Grão Mogol, pelo menos a granada piropo seria esperada de se encontrar, já que os outros minerais de mesma filiação ultrabásica são menos resistentes aos processos geológicos sofridos pela seqüência sedimentar do Supergrupo Espinhaço.

Particularmente ao Distrito de Grão Mogol, certas evidências indicam que o diamante da região possui uma origem algo mais próxima, apesar de outros fatores envolvidos também apontarem para uma fonte extra bacia. São evidências de uma origem mais próxima, a presença, embora rara, de carbonados, borts e cubos, os quais praticamente não existem na região de Diamantina. Os dois primeiros constituem tipos policristalinos que por suas próprias constituições não suportam longos transportes e, da mesma maneira que os cubos, com seus arranjos internos microfraturados, são incomuns em depósitos ressedimentados. Em conseqüência, a presença destes tipos resulta em um percentual menor de diamantes gemas. Ainda assim, os dados gerais sobre os hábitos monocristalinos (Tab. II), corroboram com uma origem "distante" para o diamante de Grão Mogol. 

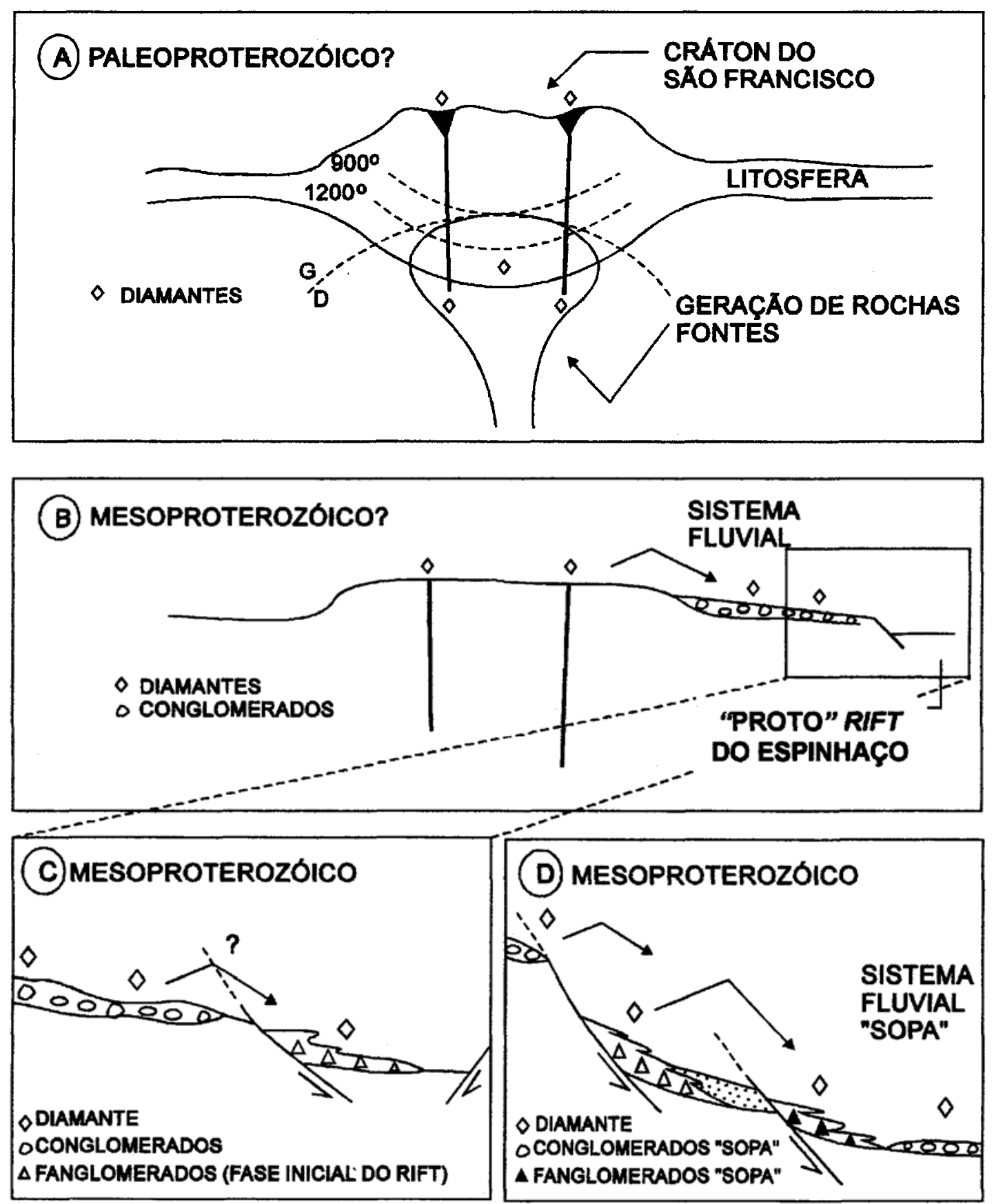

Figura 4 - Modelo esquemático do aporte dos diamantes na bacia do Espinhaço desde uma fonte cratônica. Esquema em (A) modificado de Haggerty (1986).

Com o intuito de sintetizar as informações compiladas no decorrer deste estudo, a Figura 4 mostra um possível esquema evolutivo da seqüência dos fenômenos que atuaram na região do Espinhaço, a partir da colocação das fontes primárias na região cratônica. Apesar de não serem conhecidas, as intrusões portadoras de diamantes ocorreram possivelmente no final do Paleoproterozóico (Fig. 4A). Haggerty (1986) ressaltou os argumentos apontados pela "Regra de Clifford", segundo a qual as zonas cratônicas, caracterizadas por longo período de estabilidade tectônica e por apresentarem baixo gradiente geotérmico, constituem as principais áreas de intrusão de rochas kimberlíticas. Ó magmatismo pode ser associado com a chegada de plumas do manto ou a processos metassomáticos intralitosféricos (Mitchell 1986). No início do Meso-Proterozóico, a erosão da área cratônica e a conseqüente formação de bacias periféricas, transportou os diamantes para leste, na direção do que pode ser designado de proto- rift do Espinhaço (Fig. 4B). Ainda nesta época, com a abertura do rift, as formações basais do Supergrupo Espinhaço foram depositadas, porém ainda sem receber a contribuição decisiva do sistema fluvial peri- cratônico (Fig. 4C), o que ocorreu somente em um estágio posterior com o soerguimento da área fonte e conseqüente deposição dos conglomerados diamantíferos (Fig. 4D).

CONCLUSÕES Não existe ainda, e dificilmente será encontrada uma prova definitiva assegurando uma origem do diamante da Serra do Espinhaço a partir de fontes distantes no cráton. Esta prova passaria pela descoberta de rochas ultrabásicas como kimberlitos e lamproítos nesta área, segundo o modelo clássico de colocação de tais rochas proposto por Clifford (1970) para os depósitos africanos, e que tem encontrado outros exemplos similares em diversas regiões do mundo (cf. os trabalhos de Haggerty 1986 e Janse 1994). Como porém, a porção cratônica do sudeste brasileiro na sua maior parte está recoberta pelos sedimentos do Grupo Bambuí, os quais podem atingir até 1000 $\mathrm{m}$ de espessura, considera-se assim remota a possibilidade de se encontrar pipes daquelas rochas.

Quanto à possibilidade de uma origem próxima, que nos últimos anos voltou a ser defendida por diversos geólogos que atuam no Espinhaço (p. ex., Almeida-Abreu 1993,1996, Fleischer 1995), os 
parâmetros geológicos, mineralógicos e gemológicos que permitissem sua comprovação foram sistematicamente testados. Estes autores basearam-se em modelos teóricos envolvendo extensas regiões, dando relativamente pouca importância ao principal ponto que a questão abrange: o diamante, suas características físicas e minerais indicadores. Relacionando tais parâmetros, conforme os objetivos deste estudo, podemos concluir que:

(1) A presença de clastos conglomeráticos dentro do Conglomerado Sopa, evidencia a ocorrência de dois ou mais períodos pretéritos envolvendo diagênesé, soerguimento e erosão. Ou seja, mesmo se considerando o caráter proximal daquela rocha, não existe a obrigatoriedade de que os diamantes tenham uma rocha fonte primária nas imediações do sítio de sedimentação;

(2) Os teores médios em kimberlitos e lamproítos diamantíferos variam preferencialmente entre $1-3 \mathrm{ct} / \mathrm{m}^{3}$, ainda que o lamproíto de Argyle (Austrália) apresente o teor excepcional de $18 \mathrm{ct} / \mathrm{m}^{3}$ (Helmstaedt 1993, Janse 1993). Os conglomerados diamantíferos do Espinhaço apresentam um fator de diluição muito mais alto, com teores médios variando entre 0,01 e $0,10 \mathrm{ct} / \mathrm{m}^{3}$ em todos os seus locais de ocorrência.

(3) Existindo fontes próximas, alguns dos minerais mais resistentes aos processos de intemperismo e ao metamorfísmo superposto ao Supergrupo Espinhaço poderiam ter sobrevivido. Neste sentido foi procurado diretamente um dos mais resistentes de tais minerais, que é a granada piropo. Uma extensa amostragem de prospecção de minerais pesados envolvendo os conglomerados e os clastos de conglomerados, assim como os sedimentos aluvionares derivados, não revelou a presença deste ou de outros minerais;
(4) Diamantes de fontes primárias possuem características próprias, conforme reveladas pelo estudo de milhares de cristais de kimberlitos africanos e dos lamproítos australianos (Harris et al 1975,1979; Hall \& Smith 1984). Entre estas, ressaltam-se os predomínios de cristais quebrados e a presença dos tipos borts. No Espinhaço, ao contrário, essas formas são raríssimas e em diversos locais elas praticamente não ocorrem;

(5) Kimberlitos se caracterizam pela maior proporção de cristais com hábito octaédrico em relação aos de hábito rombododecaédrico. Esta última forma é típica de depósitos sedimentares distantes, pelas próprias condições hidrodinâmicas que ela originalmente apresenta, ou seja, maior número de faces, as quais são arredondadas pela dissolução natural atuante no meio magmático. No Espinhaço os rombododecaedros são predominantes;

(6) O percentual de diamantes de qualidade gemológica nas rochas primárias é reduzido em relação aos diamantes industriais. Nestas, além da já mencionada alta freqüência de cristais quebrados e dos borts, também são altas as taxas de cristais com inclusões e/ou jaçados, cristais geminados e monocristais de hábito não gemológico, como o cubo. Quantificando esses dados, kimberlitos e lamproítos apresentam normalmente entre 5 e $20 \%$ de cristais gemológicos (Janse 1993). No Espinhaço, tais valores variam em geral na faixa de $80-90 \%$ de gemas, alcançando porém em Jequitaí um máximo de $97 \%$. São dados muito semelhantes aos encontrados na costa africana da Namíbia, onde os diamantes além do transporte fluvial, sofreram reconcentração em zonas sujeitas a ressaca no ambiente marinho raso, e assim quase $100 \%$ dos seus diamantes são gemológicos.

\section{Referências}

Almeida-Abreu, P.A. 1993. A evolução geodinâmica cia Serra cio Espinhaço Meridional, Minas Gerais, Brasil. Freiburg, 150 p. (Tese de Doutoramento, Albert-Ludwigs-Universitát)

Almeida-Abreu, P.A. 1996. O caminho das pedras. Geonomos, 4:77-93.

Barbosa, 0.1991. Diamante no Brasil: histórica, ocorrência, prospecção e lavra. Brasília, CPRM. 136p.

Censier, C.; Tourenq, J. 1995. Crystal forms and surface textures of alluvial diamonds from the western region of the Central African Republic. Mineral. Deposita, 30:314-322.

Chaves, M.L.S.C. 1997. Geologia e mineralogia do diamante da Serra do Espinhaço en Minas Gerais. São Paulo, 289 p. (Tese de Doutoramento, IG/Univ. São Paulo).

Chaves, M.L.S.C. e Uhlein, A. 1991. Depósitos diamantíferos da região do Alto/Médio Rio Jequitinhonha, Minas Gerais. In: Schobbenhaus, C.; Queiroz, E.T.; Coelho, C.E.S., eds. Principais depósitos minerais do Brasil, v.IV-A. Brasília, DNPM/CPRM. p.1 17-138.

Chaves, M.L.S.C. e Karfunkel, J. 1993. Euclásio na região de Gouveia, Minas Gerais. In: Simpósio de Geologia de Minas Gerais, 7, Belo Horizonte, 1993. Anais... Belo Horizonte, SBG-MG, p. 115-117.

Chaves, M.L.S.C.; Karfunkel, J. 1997. A protobacia do Rio Jequitinhonha durante o Cretáceo Inferiore seu potencial diamantífero. Geociências, 16:191-203.

Chaves, M.L.S.C.; Dupont, H.; Karfunkel, J.; Svisero, D.P. 1993. Depósitos diamantíferos de Minas Gerais: uma revisão. In: Simpósio de Geologia do Diamante, 1, Cuiabá, 1993. Anais... Cuiabá, UFMT, p.79-100.

Chaves, M.L.S.C.; Karfunkel, J.; Wegner, R. 1997. Diamantvorkommen von Grão Mogol: Geologische und gemologische Untersuchungen in Minas Gerais, Brasilien. Geowissenschqften, 15:73-78.

Clifford, T.N. 1970. The structural framework of Africa. In: Clifford, T.N. e Glass, I.G., eds., African magmatism and tectonics. Edinburgh, Oliver and Boyd. p. 1 -26.

Dossin, I.A.; Dossin, T.M.; Chaves, M.L.S.C. 1990. Compartimentação estratigráfica do Supergrupo Espinhaço em Minas Gerais - os grupos Diamantina e Conselheiro Mata. Rev. Bras. Geoc., 20:178-186.

Eschwege, W.L. v. 1833. Pluto Brasiliensis. Berlin, Weimer. 622p.

Fersman, A. Von e Goldschmidt, V. 1911. Der Diamant. Heidelberg, Carl Winters. 274p.

Fleischer, R. 1995. Prospecção e economia do diamante da Serra do Espinhaço. Geonomos, 3:27-30

Freise, F.W. (1930) - Der Mineralbestand der Konglomerate von Diamantina, Staat Minas Gerais, Brasilien, Chemie derErde, B6:66-71.

Freyberg, B. v. 1934. Die Bodenschatze dês Staates Minas Geraes (Brasilien). Stuttgart, E. Schweizerbart'sche. $453 \mathrm{p}$.

Gaal, R.A.P. 1977. The diamond dictionary. Santa Monica, Gemological Institute of America. 342p

Garcia, A.J.V. e Uhlein, A. 1987. Sistemas deposicionais do Supergrupo Espinhaço na região de Diamantina (MG). In: Simpósio sobre Sistemas Deposicionais no Pré-Cambriano, Ouro Preto, 1987. Anais... Ouro Preto, SBG-MG, p.1 13-135.

Gonzaga, G.M.; Teixeira, N.A.; Gaspar, J.C. 1994. The origin of diamonds in western Minas Gerais, Brazil. Mineral. Deposita, 29:414-421.

Guimarães, D. 1934. À margem de "Os satellites do diamante". Belo Horizonte, Serviço Geológico do Estado de Minas Gerais. Monografia 2. 58p.

Haggerty, S.E. 1986. Diamond genesis in a multiple-constrained model. Nature, 320: 34-38.

Hall, A.E. e Smith, C.B. 1984. Lamproite diamonds - are they different? In: Glover, J. e Harris, P., eds., Kimberlites occurrences and origins. Univ. of Western Australia, Geology Depart. Publ. v.8. p. 167-212.

Hallam, C.D. 1964 The geology of the coastal diamond deposits of southern Africa (1959). In: Haughton, S.H., ed., The geology of some ore deposits in southern Africa. Johannesburg, Geological Society of South Africa, v.2. p.671-728,
Haralyi, N.L.E. e Svisero, D.P. 1986. Geologia e análise estatística do diamante da Mina da Boa Vista, Diamantina. In: Congresso Brasileiro de Geologia, 34, Goiânia, 1986. Anais... Goiânia, SBG. v.6. p.2297-2311.

Haralyi, N.L.E.; Hasui, Y.; Morales, N. 1991. O diamante pré-cambriano da Serra do Espinhaço, MG. In: Schobbenhaus, C.; Queiroz, E.T.; Coelho, C.E.S., eds., Principais depósitos minerais do Brasil, v.IV-A. Brasília, DNPM/CPRM. p.1 17-138.

Harris, J.H.; Howthorne, J.B.; Oosterveld, M.; Wehmeyer, E. 1975. A classification scheme for diamond and comparative study of South African diamond characteristics. Phys. Chem. Earth, 9:765-783.

Harris, J.W.; Hawthorne, J.B.; Oosterveld, M. 1979. Regional and local variations in the characteristics of diamonds from some southern african kimberlites. In: Boyd, F.R. e Meyer, H.O.A., eds., Kimberlites, diatremes and diamonds: their geology, petrology, and geochemistry. Washington, American Geophysical Union, p.27-41.

Helmreichen, V. v. 1846. Über das Geognostische Vorkommen der Diamanten und ihre Gewinnungs-methoden auf der Serra do Grão Mogor. Wien, Braunmiiller \& Seidel. $74 \mathrm{p}$.

Helmstaedt, H.H. 1993. Natural diamond occurrences and tectonic setting of "primary" diamond deposits. In: Diamonds: exploration, sampling and evaluation. Toronto, Proceedings of a short course presented by the Prospectors and Developers Association of Canada, p.3-72.

Herrgesell, G. 1984. Das Prakambrium am Ostrand der nordlichen Serra do Cipó (Serra do Espinhaço, Minas Gerais, Brasilien). Freiberg, 247p. (Dissertation zur Erlangung dês Doktorgrades, Albert-Ludwigs-Universitãt).

Hussak, E. 1917. Os satellites do diamante. Rio de Janeiro, Serviço Geológico e Mineral. do Brasil. 55p.

Janse, A.J.A. 1993. The aims and economic parameters of diamond exploration. In: Diamonds: exploration, sampling and evaluation. Toronto, Proceedings of a short course presented by the Prospectors and Developers Association of Canada. p. $173-184$.

Janse, A.J.A. 1994. Is Clifford's rule still valid? Affirmative examples around the world. In: International Kimberlite Conference, 5, Araxá, 1991. Proceedings... Araxá Brasilia, CPRM Publ. v.2. p.215-235.

Kaminski, F.V. (1994) - Carbonado and yakutite: properties and possible genesis. In International Kimberlite Conference, 5, Araxá, 1991. Proceedings... Araxá Brasília, CPRM Publ. v.2. p. 136-143.

Karfunkel, J. e Chaves, M.L.S.C. 1995. Conglomerados cretácicos da Serra do Cabral (MG): um modelo para a redistribuição coluvio-aluvionar dos diamantes do Médio São Francisco. Geociências, 14:59-72.

Karfunkel, J.; Chaves, M.L.S.C.; Svisero, D.P.; Meyer, H.O.A. 1994. Diamonds from Minas Gerais, Brazil: an update an sources, origin and production. Internal. Geol. Rev., 36:1019-1032.

Karfunkel, J.; Chaves, M.L.S.C.; Hoppe, A.; Banko, A. 1996. Diamanten des Espinhaço-Gebirges (Minas Gerais, Brasilien): Gemmologische und õkonomische Folgen geologischer Geschichte. Z. Dt. Gemmol. Ges., 45: 113-128.

Leite, C.R. 1969. Mineralogia e cristalografia do diamante do Triângulo Mineiro. São Paulo, 102 p. (Tese de Doutoramento, FFCL/Univ. São Paulo).

Levison, A.A.; Gurney, J.J.; Kirkley, M.B. 1992. Diamond sources and production: past, present, and future. Gems \& Gemology, 28:234-254

Linari-Linholm, A. A. 1973. The occurrence, mining, and recovery of diamonds. London, De Beers Consolidated Mines. 44p.

Martins Neto, M, A. 1993. The sedimentary evolution of a Proterozoic rift basin: the basal Espinhaço Supergroup, Southern Serra do Espinhaço, Minas Gerais, Brazil. Freiburg, 155p. (Tese de Doutoramento, Albert-Ludwigs-Universitát). 
Meyer, H.O. e Svisero, D. 1975. Mineral inclusions in Brazilian diamonds. Ph|s. Chem. Earth, 9:785-795.

Mitchell, R.H. 1986. Kimberlites: mineralogy, geochemistry, petrology. New York, Plenum Press. 442 p.

Moore, M. e Lang, A.R. 1974. On the origin of the rounded rhombic dodecahedral habit of natural diamond. Jour. Cryst. Growth, 26:133-139.

Moraes, L. J. 1934. Depósitos diamantíferos no norte do Estado de Minas Gerais. Rio de Janeiro, DNPM/SFPM, 61 p. (Boletim 3).

Moraes, L.J. e Guimarães, D. 1930. Geologia da região diamantífera do norte de Minas Gerais. An. Acad. Brás. CL, 2:153-186.

Moryioshi, Y.; Kamo, M.; Setaka, N.; Sato, Y. 1983. The microstructure of natural polycristal diamond, carbonado and bailas. Jour. Mater. Sci., 18:217-224

Munhóz, D.T.V. 1981. Estudo dos minerais pesados dos metaconglomerados e metabrechas da Formação Sopa-Brumadinho. Belo Horizonte, Mineração Tejucana. 43p. (Relatório Inédito).

Orlow, Y.L. 1973. Mineralogy of the diamond. New York, John Wiley \& Sons. 235p

Patel, A.R. e Agarwal, M.K. 1965. Microstructures on Panna diamonds surfaces. Amer. Min., 50:124-131.

Pflug, R. 1965. A geologia da parte meridional da Serra do Espinhaço e zonas adjacentes, Minas Gerais. Rio de Janeiro, DNPM/DGM, 55p. (Boletim 226).

Schobbenhaus, C. 1993. O Proterozóico Médio no Brasil com ênfase à Região Centro-Leste. Freiburg, 166 p. (Tese de Doutoramento, Albert-Ludwigs-Universitat).

Schölll, W.U. e Turinsky, F. 1980. O espectro de minerais pesados nas seqüências quartzíticas pré-cambrianas na parte sul da Serra do Espinhaço, Brasil. Münster. Forsch. Geol. undPalaont., 51:257-278.
Shibata, K.; Kamioka, H.; Kaminsky, F.V.; Koptil, V.I.; Svisero, D.P. 1993. Rare earth elements patterns of carbonado and yakutite: evidence for their crustal origin. Mineral. Mag., 57:607-611

Sutherland, D.G. 1982. The transport and sorting of diamonds by fluvial and marine processes. Earn. Geol, 77:1613-1620.

Svisero, D.P. 1969. Microscopia eletrônica de estruturas de superfície em cristais de diamantes do Brasil. São Paulo, 38 p. (Tese de Mestrado, FFCL/Univ São Paulo).

Svisero, D.P. 1971. Mineralogia do diamante da região do Alto Araguaia, MT. São Paulo, 137 p. (Tese de Doutoramento, IGA/Univ. São Paulo).

Svisero, D.P. 1978. Composição química, origem e significado geológico de inclusões minerais de diamantes do Brasil. São Paulo, 165 p. (Tese de Livre Docência, IG/Univ. São Paulo).

Svisero, D.P. e Haralyi, N.L.E. 1985. Caracterização do diamante da Mina de Romaria, MG. In: Simpósio de Geologia de Minas Gerais, 3, Belo Horizonte, 1985. Anais... Belo Horizonte, SBG-MG, p.140-153.

Tompkins, L. e Gonzaga, G.M. 1989. Diamonds in Brazil and a proposed model for the origin and distribution of diamonds in the Coromandel region, Minas Gerais, Brazil. Econ. Geol., 84:591-602.

Williams, A.F. 1932. The genesis of the diamond. London, Ernest Benn. 636p.

Manuscrito A-947

Recebido em 22 de novembro de 1997 Revisão dos autores em 13 de abril de 1998 Revisão aceita em 15 de abril de 1998 